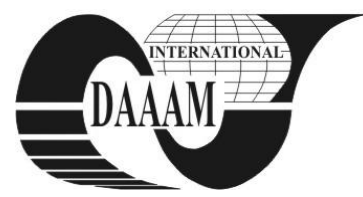

Annals of DAAAM for 2011 \& Proceedings of the 22nd International DAAAM Symposium, Volume 22, No. 1, ISSN 1726-9679 ISBN 978-3-901509-83-4, Editor B. Katalinic, Published by DAAAM International, Vienna, Austria, EU, 2011 Make Harmony between Technology and Nature, and Your Mind will Fly Free as a Bird

Annals \& Proceedings of DAAAM International 2011

\title{
STRUCTURAL IMPROVEMENT OF HYDRAULIC SHEARING MACHINE
}

\author{
VOSNIAKOS, G[eorge] C[hristopher] \& KARYOTIS, M[ichael]
}

\begin{abstract}
Structural sufficiency of an industrial hydraulic shear to safeguard quality of the cuts is investigated by $3 D$ finite element modeling of base and guillotine of the machine tool. Shearing forces are calculated analytically and rams as well as guillotine hinges are represented by calculated actions and reactions accordingly. Reinforcement with ribs and structural sheet thickening are investigated in alternative models, the ribs giving a reduction of maximum blade gap by a factor of 3 . Torsional resistance of the guillotine cannot be sufficiently increased pointing to a control solution in the hydraulic circuit. Key words: deformation, FEA, machine tool, clearance
\end{abstract}

\section{INTRODUCTION}

Structural analysis of a crankshaft-driven guillotine shearing machine used Finite Element Analysis (FEA) to examine vibration characteristics for different upper and lower blade carrying plate thickness (Ramamurthi et al, 1997). An analytical model of press brake bending using Timoshenko beam theory lead to optimisation of shape, dimensions and initial deformation of the machine to minimise bending error (Coelho et al, 2005). Modular machine modelling to reduce lengthy model preparation time in FEA has been advocated employing various mixtures of rigid and elastic body idealisation (Kono et al, 2010) and pre-calculated FE discretised structures (Zatarain et al., 1998). Still comprehensive modelling towards a virtual machine tool remains a challenge (Altintas et al., 2005).

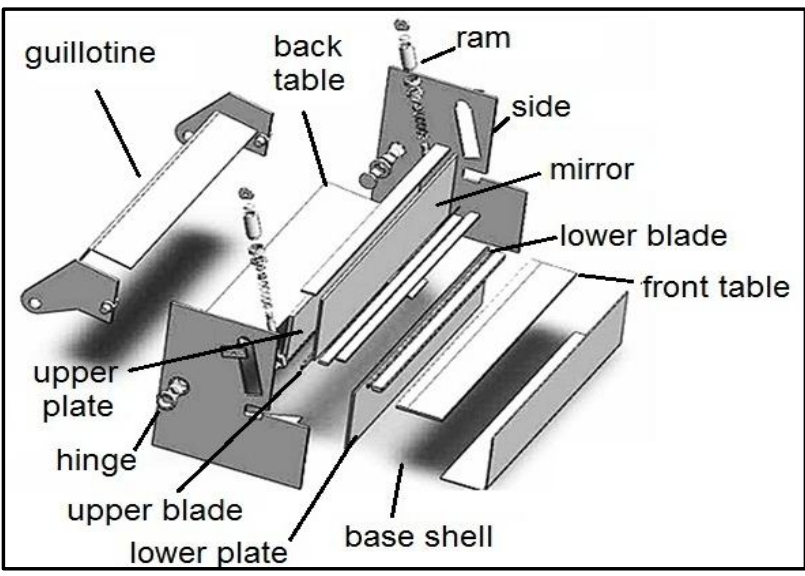

Fig. 1. Main elements of a hydraulic shear machine.

This paper investigates structural modifications on a particular industrial hydraulic shear. A typical machine consists of the base including the table on which the lower blade is fixed, the rotary guillotine on which the upper blade is fixed, two hydraulic rams operating the guillotine at either side and hinges between base and guillotine, see Fig.1. The machine has $6 \mathrm{~mm}$ cutting capacity (St 42 ), $1.4^{\circ}$ cutting angle, $3100 \mathrm{~mm}$ cutting length, 255 bar max hydraulic pressure, $11 \mathrm{~kW}$ power, overall dimensions $3820 \times 3835 \times 1820 \mathrm{~mm}$ and $7 \mathrm{tn}$ weight.
The first aim is to reduce the clearance increase resulting from horizontal displacement of both shear blades, which varies during the shearing process as the cutting point moves along the table. According to industrial practice horizontal deformation should be up to $20 \%$ of nominal shear blade gap, which is set by the machine operator to $3-10 \%$ of sheet thickness. Too large a clearance causes bending and failure instead of shearing.

The second aim is to reduce torsional deformation of the guillotine which results from inability of the hydraulic system to adjust continuously, independently and fast enough the flow to the hydraulic cylinders in accordance to the movement of the cutting point along the span of the table. This necessitates the guillotine to be shaped into a relatively heavy shell.

\section{MACHINE TOOL MODELING}

The machine tool consists of 63 parts that were modelled on the Solidworks CAD-CAE package. They were assembled as four block types, namely: machine base, guillotine, ram and hinge and their functionality was ensured by 38 mating constraints. In subsequent numerical analysis rams and hinges were considered too complex to be retained as detailed models, therefore they were replaced by appropriate loads that were calculated analytically as in Section 3. Thus, the guillotine and the machine base were run as separate models, see Fig.2.

Average mesh element was $32 \mathrm{~mm}$ for the guillotine and 36 $\mathrm{mm}$ for the machine base. Tolerance was $1.6 \mathrm{~mm}$ for the guillotine and $1.8 \mathrm{~mm}$ for the machine base.
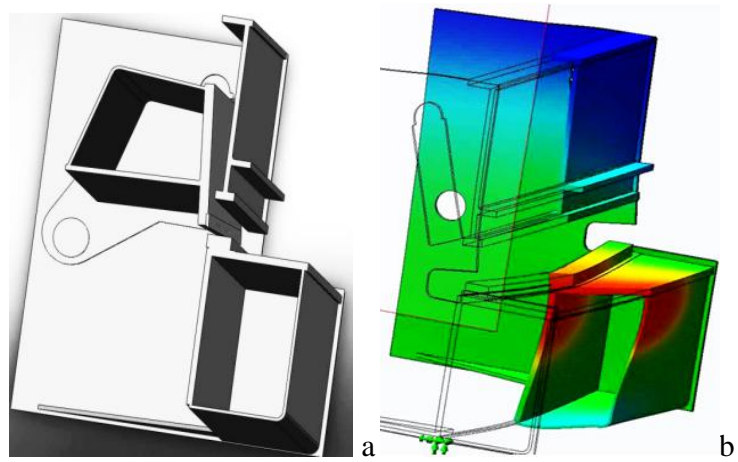

Fig. 2 (a) Sectioned machine assembly (b) Deformed base

\section{LOAD MODELLING}

Vertical shearing force component is given as:

$$
F_{v}=\sigma_{v} t^{2} / 2 \tan \alpha
$$

Where: $\sigma_{v}=0.7-0.9$ UTS, $\mathrm{t}:$ sheet thickness, $\alpha$ : angle of shear

Horizontal $\left(\mathrm{F}_{\mathrm{h}}\right)$ to vertical $\left(\mathrm{F}_{\mathrm{v}}\right)$ component ratio of shearing force equals to $1 / 3$ theoretically, but to $1 / 5$ practically. In the case investigated the limit force was considered, corresponding to $\mathrm{t}=6 \mathrm{~mm}, \alpha=1.4^{\circ}$, UTS $=440 \mathrm{~N} / \mathrm{mm}^{2}$, resulting in $F_{v}=291.659$ $\mathrm{N}$ and $F_{h}=97.220 \mathrm{~N}$. 


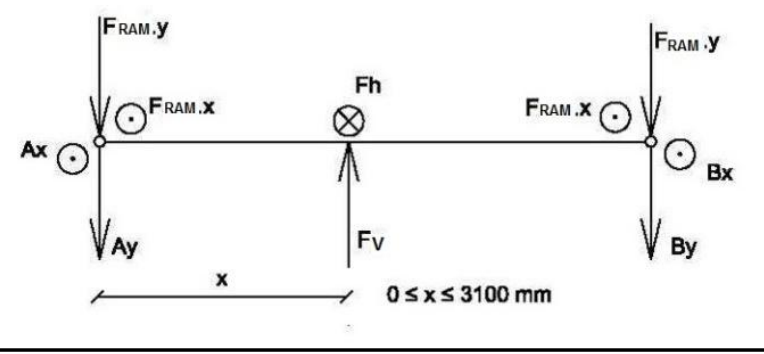

Fig. 3 Free body diagram of rotary guillotine.

This load is calculated at 13 discrete triangular surfaces positions along the blade at a distance $\mathrm{x}$ from left edge,see Fig. 3 , thereby simulating the cutting force 'travel' in the process.

Trivial force and moment equilibrium yield hinge reactions Ax, Ay, Bx, By as a function of $F_{v}, F_{h}, F_{\text {RAM }}$ and $x$, see Fig. 3 . Considering that the vertical force component results in a moment that is equally distributed between the two supports, Ram force has to be able to produce the opposite moment to achieve equilibrium. In the limit force case this gives $\mathrm{F}_{\mathrm{RAM}}=156.732 \mathrm{~N}$. Note that maximum ram force is $188.345 \mathrm{~N}$.

\section{RESULTS AND DISCUSSION}

\subsection{Rotary guillotine deformation}

The initial guillotine configuration produces displacement larger than $120 \mu \mathrm{m}$, see Fig.4. Two variants were designed at an extra weight of 71 and $32 \mathrm{~kg}$, see Fig.5, with two reinforcing ribs of $15 \mathrm{~mm}$ thickness and with $2 \mathrm{~mm}$ thicker horizontal spar. Maximum displacement dropped thus to $32 \mu \mathrm{m}$ and $166 \mu \mathrm{m}$ respectively, see Fig. 4.

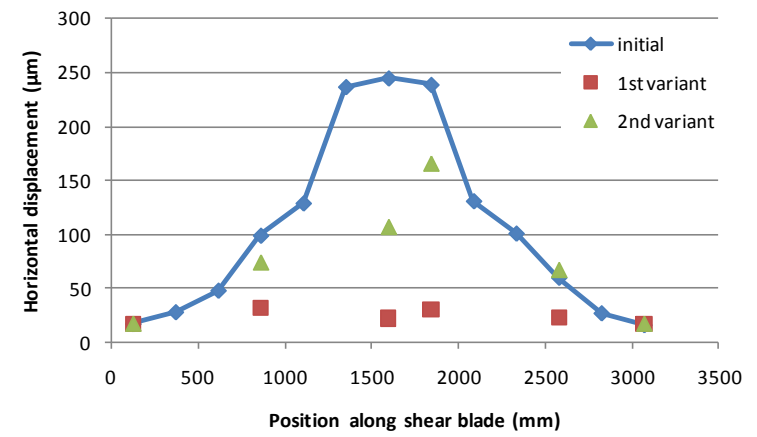

Fig. 4 Upper blade displacement (guillotine deformation)

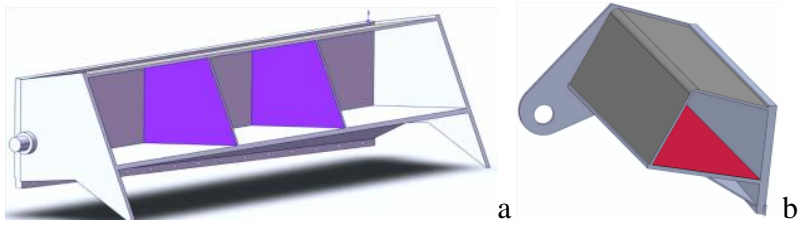

Fig. 5 Guillotine variants (a) Ribbed (b) Thicker spar

\subsection{Base deformation}

The initial configuration of the base gives high blade displacement reaching $322 \mu \mathrm{m}$,see Fig. 6 . The deformation pattern is shown in Fig. 2(b). Deformation of the rotary guillotine is analogous to that of the base due to their active shapes being similar, see Fig. 2(a). Two variants of the base were tried, with two $15 \mathrm{~mm}$ thick reinforcing ribs and with $5 \mathrm{~mm}$ thicker front table, see Fig. 7. Displacement was reduced to $155 \mu \mathrm{m}$ for the first variantand $304 \mu \mathrm{m}$ for the second variant, at an extra mass of $74 \mathrm{~kg}$ and $50 \mathrm{~kg}$ respectively.

\subsection{Rotary guillotine torsion}

The initial configuration relies on a closed shell and results in max vertical displacement of $2043 \mu \mathrm{m}$. A variation using a
$15 \mathrm{~mm}$ thick shell around the full profile, see Fig. 8, lowers displacement to $945 \mu \mathrm{m}$ at an extra weight of $721 \mathrm{~kg}$, but obstructs reach inside this shell. It soon became apparent that by modifying the existing design without major weight addition torsional deformation cannot be substantially lowered.

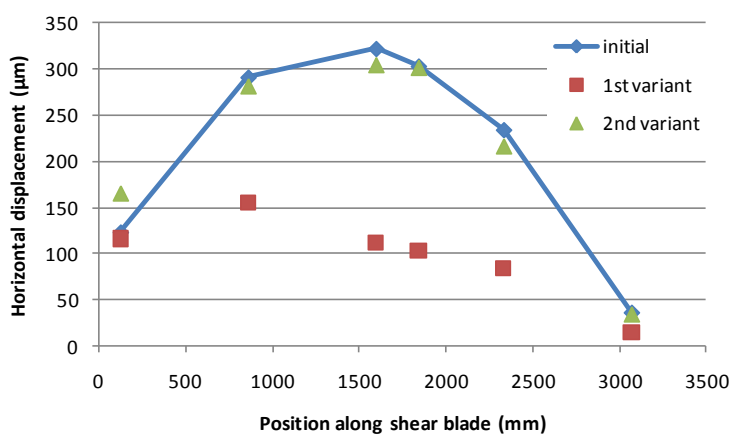

Fig. 6 Lower blade displacement (base deformation)
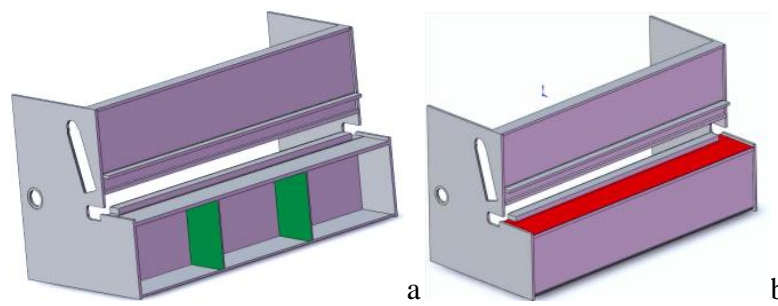

Fig. 7 Machine base variants (a) Ribbed (b) Thicker table sheet

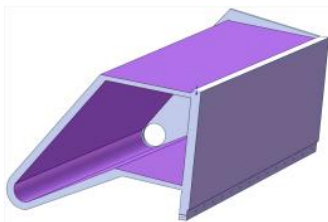

Fig. 8 Guillotine variant

\section{CONCLUSION}

Horizontal displacement between blades in the initial configuration reaches $567 \mu \mathrm{m}$ for $6 \mathrm{~mm}$ steel sheet thickness fae beyond the limit of $120 \mu \mathrm{m}$. First experimentation shows rib reinforcements to reduces displacement to a more tolerable 187 $\mu \mathrm{m}$ at a negligible extra weight and cost. Making sheet thicker has much lower influence, reaching displacement of $467 \mu \mathrm{m}$. Initial experimentation regarding guillotine torsional deformation by modifying existing design was not promising, pointing to the fundamental deficiency of the hydraulic circuit in fast continuous regulation of the flow in each cylinder.

\section{REFERENCES}

Altintas, Y.; Brecher, C.; Weck, M. \& Witt, S. (2005). Virtual Machine Tool. CIRP Annals - Manufacturing Technology, 54, 2, 115-138

Coelho, P.G.;. Fariab, L.O \& Cardoso, J.B. (2005). Structural analysis and optimisation of press brakes. International Journal of Machine Tools \& Manufacture, 45, 1451-1460.

Kono, D.; Lorenzer, T.; Weikert, S. \& Wegener, K. (2010). Evaluation of modelling approaches for machine tool design. Precision Engineering, 34, 399-407

Ramamurti, V.; Sasikiran, S. \& Kumar, V. (1997). Dynamic analysis of a guillotine shearing machine. Journal of Materials Processing Technology, 71, 202- 214

Brecher, C.; Esser, M. \& Witt, S. (2009). Interaction of manufacturing process and machine tool. CIRP Annals Manufacturing Technology, 58, 1, 588-607 